\title{
Racial discrimination and allostatic load among First Nations Australians: a nationally representative cross-sectional study
}

\author{
Leah Cave ${ }^{1,2^{*}}\left(\mathbb{D}\right.$, Matthew N. Cooper ${ }^{1}$, Stephen R. Zubrick ${ }^{1,3}$ and Carrington C. J. Shepherd ${ }^{1,4}$
}

\begin{abstract}
Background: Increased allostatic load is linked with racial discrimination exposure, providing a mechanism for the biological embedding of racism as a psychosocial stressor. We undertook an examination of how racial discrimination interacts with socioecological, environmental, and health conditions to affect multisystem dysregulation in a First Nations population.

Methods: We conducted latent class analysis (LCA) using indicators of life stress, socioeconomic background, and physical and mental health from a nationally representative sample of Australian Aboriginal adults $(N=2056)$. We used LCA with distal outcomes to estimate the effect of the latent class variable on our derived allostatic load index and conducted a stratified analysis to test whether allostatic load varied based on exposure to racial discrimination across latent classes.

Results: Our psychosocial, environmental, and health measures informed a four-class structure; 'Low risk', 'Challenged but healthy', 'Mental health risk' and 'Multiple challenges'. Mean allostatic load was highest in 'Multiple challenges' compared to all other classes, both in those exposed $(4.5 ; 95 \% \mathrm{Cl}$ : 3.9, 5.0) and not exposed $(3.9 ; 95 \% \mathrm{Cl}: 3.7,4.2)$ to racial discrimination. Allostatic load was significantly higher for those with exposure to racial discrimination in the 'Multiple challenges' class $(t=1.74, p=.04)$ and significantly lower in the 'Mental health risk' class $(t=-1.67, p=.05)$.

Conclusions: Racial discrimination may not always modify physiological vulnerability to disease. Social and economic contexts must be considered when addressing the impact of racism, with a focus on individuals and sub-populations experiencing co-occurring life challenges.
\end{abstract}

Keywords: Racial discrimination, Allostatic load, Latent class analysis

\section{Background}

Racial discrimination is a well-established contributor to adverse physical health outcomes in ethnic/cultural minority populations [1-6]. Evidence detailing how racial discrimination affects physiology within the context of broader life circumstances is needed to encourage the

\footnotetext{
* Correspondence: leah.cave@telethonkids.org.au

'Telethon Kids Institute, The University of Western Australia, PO Box 855, West Perth, Western Australia 6872, Australia

${ }^{2}$ School of Population and Global Health, The University of Western Australia, 35 Stirling Highway, Perth, Western Australia 6009, Australia

Full list of author information is available at the end of the article
}

development of informed strategies to prevent or eradicate racism in the settings where it occurs. This approach is particularly essential for Indigenous populations within high-income countries, where racial discrimination is often compounded by ongoing social marginalisation, land dispossession, and loss of sovereignty [7].

In Australian Aboriginal and Torres Strait Islander (hereafter referred to as 'Aboriginal') populations, where the pervasiveness of racial discrimination is well documented across legal, healthcare, educational and employment settings, [8-10] assessing the link between the

C C The Author(s). 2020 Open Access This article is licensed under a Creative Commons Attribution 4.0 International License, which permits use, sharing, adaptation, distribution and reproduction in any medium or format, as long as you give appropriate credit to the original author(s) and the source, provide a link to the Creative Commons licence, and indicate if changes were made. The images or other third party material in this article are included in the article's Creative Commons licence, unless indicated otherwise in a credit line to the material. If material is not included in the article's Creative Commons licence and your intended use is not permitted by statutory regulation or exceeds the permitted use, you will need to obtain permission directly from the copyright holder. To view a copy of this licence, visit http://creativecommons.org/licenses/by/4.0/ The Creative Commons Public Domain Dedication waiver (http://creativecommons.org/publicdomain/zero/1.0/) applies to the data made available in this article, unless otherwise stated in a credit line to the data. 
psychosocial stressor of racism and physical health remains a challenge. To date, indicators of physical health most commonly comprise self- or carer-rated general health status, with few significant associations found [11-16]. Self-reported general health can be a misleading indicator of physical health, particularly for socially disadvantaged populations who may underreport or understate adverse health outcomes [17, 18]. Clinical biomarkers present a stronger indicator of underlying biological risk factors or early precursors of disease, and are typically unrecognised or not acknowledged by individuals responding to general health self-report measures. Individual biomarkers for allostatic load have been observed to be significantly higher in Aboriginal compared with non-Aboriginal populations [19] and studies have begun to investigate the association between racism and individual biomarkers in Aboriginal populations [20-24]. However, single biomarkers are specific to individual physiological systems and cannot capture the interactions and adaptions occurring between systems which lead to dysregulation.

Allostatic load is an indicator of multisystem physiological dysregulation resulting from over- or underactivation of systems designed to adapt to stress (i.e. metabolic, cardiovascular, immune, and neuroendocrine systems) [25]. Long periods of repeated exposure to psychosocial stressors such as racial discrimination are proposed to increase allostatic load, [26] promoting pathophysiology and ultimately increasing morbidity and mortality [27]. Increased allostatic load has also been linked to multiple other markers of stress and adversity, including socioeconomic status [27-31]. Associations between racial discrimination and allostatic load indices that comprise multiple biomarkers have been established in international studies [32-45]. Two of these studies were focused on Indigenous adults attending university in western Canada $[39,40]$. In these Canadian studies, childhood experiences of racial discrimination and past year experiences of racial discrimination were both significantly associated with an allostatic load index comprised of seven biomarkers. The sample was dichotomised into groups with high and low cultural continuity, as defined by engagement in cultural practices and values related to their Indigenous cultural heritage at the time of data collection. Both studies observed that cultural continuity buffered the harmful effects of racial discrimination on allostatic load, with the association reduced to non-significance for those with high cultural continuity $[39,40]$. Several studies have situated racism within the multiple intersecting stressors known to be implicated in heightened allostatic load but did so using mediation analysis or analysis of effect modification to investigate the role of specific variables measuring single environmental factors, such as emotional support, [37] social support, [43] racial background, [32, 33, 44] and socioeconomic status [32, 34]. Studies utilising this form of variable-centred analysis are less focused on examining the effects of multiple shared characteristics within population groups than on specified pathways between exposure and outcome variables. In contrast, person-centred analysis permits an examination of how racism is situated within-rather than isolated from-the complex reality of intersecting supports and stressors present within individual lives. Latent class analysis (LCA) is a form of person-centred analysis which identifies clusters or patterns of shared characteristics within groups of people and explores how outcomes of interest differ between these groups [46]. In this study, a latent class approach was used to determine whether exposure to racial discrimination could increase allostatic load for groups of people already experiencing many psychosocial stressors and adverse health, investigating whether racial discrimination can measurably increase allostatic load in the context of competing stressors and challenging circumstances.

This study undertakes the first examination of the role of racial discrimination on allostatic load in the context of broader socioecological, environmental, and health risk factors within a First Nations population. A more nuanced understanding of the role of racism is important in supporting intervention studies and policy approaches that seek to address the persistent impact of racism on population health disparities across the globe. We apply a latent class approach to nationally-representative data to first identify profiles of Aboriginal Australian adults defined by psychosocial stressors, environmental factors, health conditions, and mental health factors. We then examine the association between these profiles and an index of allostatic load. Finally, we examine the association between identified profiles and allostatic load after dichotomising the population into those with exposure to racial discrimination in the previous 12 months and those unexposed. Our primary objective was to determine the effect of exposure to racial discrimination on allostatic load in profiles of Aboriginal adults defined by stress-related psychosocial, environmental, and health factors.

\section{Methods}

Data were from the National Aboriginal and Torres Strait Islander Health Survey (NATSIHS) and National Aboriginal and Torres Strait Islander Health Measures Survey (NATSIHMS) components of the Australian Bureau of Statistics' (ABS) Australian Aboriginal and Torres Strait Islander Health Survey (AATSIHS) 201213. Full details of the data collection, recruitment, and sampling have been reported elsewhere [47, 48]. However, in brief, the AATSIHS selected a nationally 
representative sample of Aboriginal Australians via stratified multistage area sampling of private dwellings across remote, non-remote areas, and discrete Aboriginal and Torres Strait Islander communities nationally. The AATSIHS collected comprehensive health information from the Aboriginal population to obtain national benchmark information on health-related issues, collect biomarkers of chronic disease, and monitor trends in Aboriginal health. Selected adult members of the household consenting to participate undertook face-to-face interviews with trained interviewers. The AATSIHS core sample had a response rate of $79.5 \%$ fully or adequately responding households, culminating in 12,947 respondents aged 2 years and over. Adults aged 18 years and over $(n=8157)$ were invited to participate in the NATS IHMS, where biomedical data from blood and urine tests was collected. The current study analysed data from respondents within the NATSIHMS subset of the AATS IHS $(n=3293)$. The sample was weighted by the ABS to represent the national Aboriginal population as at 30 June 2011 (the estimated population benchmark from the 2011 Census of Population and Housing). Within the NATSIHMS subset, only individuals who also participated in the NATSIHS component of the AATSIHS were retained $(n=2060)$ as participant characteristics provided within this survey component informed explanatory variables within LCA. Four respondents were recorded as a 'refusal' in answering the racial discrimination measure and were excluded from further analysis, resulting in a final sample of 2056 respondents (Fig. 1).

The ABS has initiated several strategies to build and strengthen engagement with Aboriginal communities and organisations and to ensure best practice in the collection and dissemination of data from Aboriginal populations [49]. Led by the Centre of Excellence for Aboriginal and Torres Strait Islander Statistics, the ABS is guided by cultural protocols and procedures for engagement with Aboriginal peoples and communities developed in alignment with Indigenous data sovereignty principals $[49,50]$. The current study received input and guidance on the study design and interpretation of findings from the Telethon Kids Institute Social Determinants of Aboriginal Health Community Advisory Group, an advisory group comprised of Aboriginal community members from the Perth region (Western Australia) established to ensure this research was directed and approved by the local Aboriginal community.

\section{Measures}

\section{Outcome variable}

The outcome was an allostatic load index derived from 10 biomarkers selected based on their relevance in measuring physiological systems implicated in allostatic load and availability within the NATSIHMS [27]. Biomarkers frequently used in allostatic load studies represent physiological systems implicated in both the primary and secondary effects of stress exposure, including the neuroendocrine system (e.g. cortisol, epinephrine, dopamine); immune system (e.g. Interleukin-6, tumour necrosis factor-alpha, C-reactive protein); metabolic system (e.g. high density lipoprotein cholesterol, triglycerides, glucose, insulin, albumin, creatinine); cardiovascular/respiratory systems (e.g. systolic/diastolic blood pressure, peak expiratory flow, heart rate); and anthropomorphic measures (e.g. waist-to-hip ratio, body mass index) [27] The physiological systems represented in this allostatic load index reflect secondary outcomes associated with longer-term stress exposure, as biomarkers constituting primary effects were not collected within the NATSIH MS (i.e. stress hormones, cortisol, epinephrine and norepinephrine or pro- and anti-inflammatory cytokines) [27, 51]. We have used a multi-systemic composite

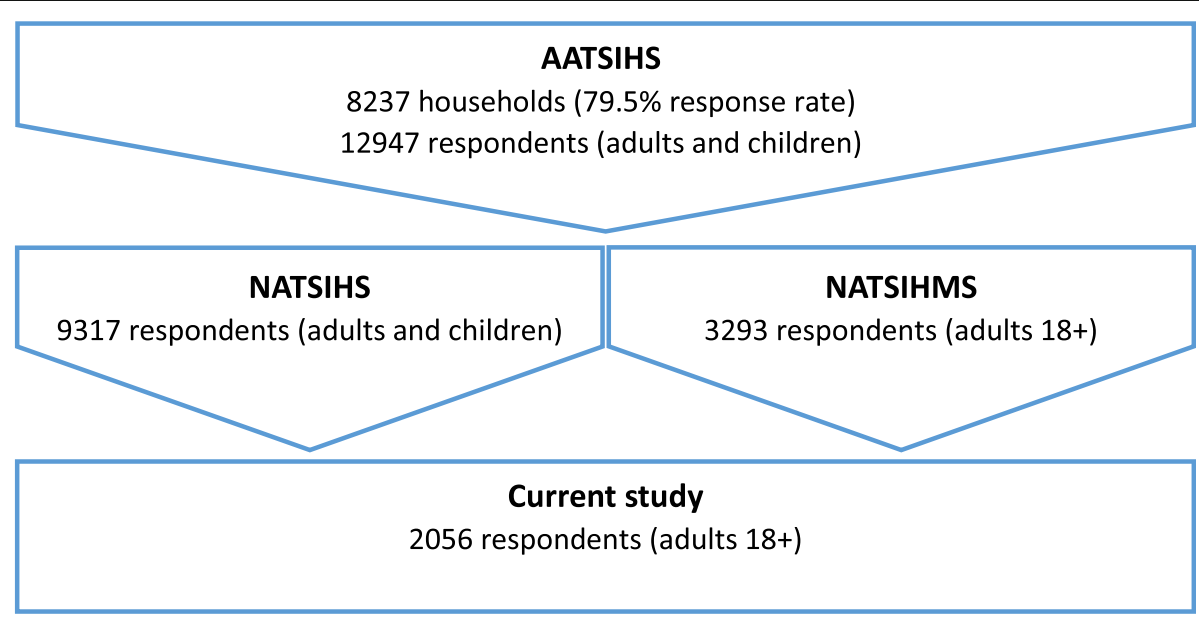

Fig. 1 Selection of the study population 
approach, including biomarkers representing several physiological systems to gain early indications of the secondary effects of stress $[27,51]$. The biomarkers included in the current study were (cardiovascular system) systolic and diastolic blood pressure; (metabolic system) high density lipoprotein- (HDL) cholesterol, low density lipoprotein- (LDL) cholesterol, triglycerides, fasting glucose, plasma glycosylated haemoglobin (HbA1c), and albumin-creatinine ratio; (anthropomorphic) body mass index; and (immune system) C-reactive protein. To derive allostatic load, participants were given a value of ' 1 ' for each biomarker that fell within the highest quartile of sample values (or the lowest quartile for HDL cholesterol), with these values then summed to a total score (index range 0-10; biomarkers weighted equally). This method has been applied to numerous studies to predict health outcomes, including later mortality, and to examine the variation produced by stress and related psychosocial factors $[27,52]$.

\section{Racial discrimination}

Respondents were asked whether they had felt they had been treated badly in the last twelve months because they were Aboriginal or Torres Strait Islander (yes/no).

\section{Explanatory variables}

Respondents within this dataset will have varying allostatic load scores based on their psychosocial, environmental, and physiological circumstances, and history. Factors that capture these circumstances have been included as explanatory variables in LCA as they will account for a portion of the variability in models of allostatic load. We selected a total of 15 explanatory variables for assessment in LCA - these factors were primarily related to stress, mental health, and physical health. Factors related to stress included low socioeconomic status (current unemployment, low education, area level disadvantage), financial difficulties, perceived social support, and death in the family. Factors related to mental health included psychological distress and a sense of control or mastery, while factors related to physical health included past or present health conditions, exercise, and having limited facilities for sanitation in the home. Geographic remoteness was also included as this can have both positive and negative implications for stress, mental health, and physical health due to either environmental and lifestyle stressors within metropolitan areas or challenges accessing services and infrastructure within remote areas. Substance use was initially included, although mean differences in allostatic load were minimal for substance use indicator variables so that stress and physical and mental health factors were ultimately prioritised for analysis.
Included variables spanned individual level $(n=10)$, family level $(n=3)$, and area level $(n=2)$ characteristics (Table 1). All explanatory variables were dichotomised with the reference category set to the low risk category, except area-level socioeconomic status which was a fivelevel categorical variable with the reference category set to the highest socioeconomic quintile.

\section{Individual level characteristics}

Individual level characteristics included health conditions, social and emotional wellbeing, exercise, education, and employment.

Health condition variables analysed $(n=4)$ included current or pre-existing kidney, cardiac, diabetes, and respiratory conditions. These condition categories were derived from 10 specific conditions reported by respondents. Respondents reporting kidney disease were classified with a 'current or pre-existing kidney condition', respondents reporting heart attack, heart failure, hypertensive disease or stroke were classified with a 'current or pre-existing cardiac condition', respondents reporting asthma, bronchitis, chronic sinusitis, or hayfever and allergic rhinitis were classified with a 'current or preexisting respiratory condition', and respondents reporting diabetes mellitus (Type 1, 2 or unknown) were classified with a 'current or pre-existing diabetes condition'. Each condition was considered present where the condition status was 'ever told has condition, still current and long-term'; 'ever told has condition, still current but not long-term'; 'ever told has condition, not current'; or 'not known or not ever told, but condition current and longterm'.

Social and emotional wellbeing variables analysed $(n=$ 3) included the Kessler Psychological Distress Scale (Kessler-5), the Multidimensional Scale of Perceived Social Support (MSPSS) and an adaption of the Pearlin Mastery Scale. The Kessler-5 measure of psychological distress is derived from 5 items in the Kessler Psychological Distress Scale-10, designed to measure levels of negative emotional states in the four weeks prior to interview [53]. Responses were categorised according to the system used by the NATSIHS and dichotomised so that high/very high scores (12-25) indicate high levels of psychological distress while low scores (5-11) indicate low levels of psychological distress [54]. The MSPSS is a measure of perceived social support from family, friends, and significant others [55] and was derived from 6 items in the NATSIHS. A score of 6-18 was then generated so that a higher score indicated reduced social support. This scale was then dichotomised by categorising those in the top decile (at or above the 90th percentile) as having 'low social support'. The Pearlin Mastery Scale measures the extent to which individuals feel in control over their life outcomes [56] and was derived from 7 items in 
Table 1 Explanatory variables and racial discrimination exposure

\begin{tabular}{|c|c|c|c|c|}
\hline Individual level characteristics & n & $\%$ & $95 \% \mathrm{Cl}$ & $\mathrm{N}^{\mathrm{a}}$ \\
\hline Current or pre-existing kidney condition & 138 & 6.8 & $5.2-8.4$ & 2056 \\
\hline Current or pre-existing cardiac condition & 836 & 40.2 & $37.2-43.2$ & 2056 \\
\hline Current or pre-existing diabetes or related condition & 693 & 31.7 & $28.9-34.4$ & 2056 \\
\hline Current or pre-existing respiratory condition & 857 & 45.6 & $42.5-48.6$ & 2056 \\
\hline Psychological distress & 617 & 30.5 & $27.7-33.4$ & 2045 \\
\hline Low social support & 129 & 12.7 & $9.9-15.4$ & 947 \\
\hline Low sense of control & 115 & 10.5 & $8.0-13.1$ & 947 \\
\hline Did not meet exercise guidelines & 507 & 53.2 & $49.0-57.5$ & 949 \\
\hline Completed Year 11 or below & 1087 & 51.1 & $47.9-54.2$ & 1989 \\
\hline Unemployed or not in the labour force & 1166 & 54.5 & $51.4-57.5$ & 2056 \\
\hline Family level characteristics & $n$ & $\%$ & & N \\
\hline Household financial stress & 1122 & 54.8 & $51.7-58.0$ & 1944 \\
\hline Family stressor - Death & 798 & 50.0 & $46.5-53.5$ & 1517 \\
\hline Limited facilities for sanitation at home & 502 & 21.0 & $18.6-23.3$ & 2054 \\
\hline Area level characteristics & $n$ & $\%$ & & N \\
\hline 1 - Most disadvantaged area & 1233 & 54.5 & $51.4-57.6$ & 2056 \\
\hline 2 & 360 & 20.5 & $17.9-23.2$ & 2056 \\
\hline 3 & 205 & 10.9 & $9.0-12.8$ & 2056 \\
\hline 4 & 187 & 10.6 & $8.7-12.5$ & 2056 \\
\hline 5 - Least disadvantaged area & 71 & 3.4 & $2.3-4.5$ & 2056 \\
\hline Living in a remote area & 1106 & 63.8 & $61.2-66.5$ & 2056 \\
\hline \multicolumn{5}{|l|}{ Racial discrimination } \\
\hline Exposure previous 12 months & 292 & 14.6 & $12.4-16.8$ & 2056 \\
\hline
\end{tabular}

the NATSIHS. A score of 7-21 was then generated so that a higher score indicated a reduced sense of control. This scale was then dichotomised by categorising those in the top decile as having a 'low sense of control'.

Exercise was derived from a single item indicating whether the amount of exercise or physical activity respondents undertook in the previous week reached 150 min as per Australian National Physical Activity and Sedentary Behaviour guidelines for adults. Respondents who did not undertake $150 \mathrm{~min}$ or more were categorised as 'did not meet exercise guidelines'. Education was derived from a single item indicating whether respondents had completed educational attainment up to Year 11 completion. Respondents who indicated they had completed up to Year 11 education or had no educational attainment were categorised as 'Completed Year 11 or below'. Employment was derived from a single item indicating whether respondents were unemployed (looking for part-time or full-time work) or not in the labour force, using a categorisation of labour force status in which the Federal Government Community Development Employment Projects scheme was included in the category of 'unemployed or not in the labour force'.
Respondents who were unemployed or not in the labour force were categorised as 'unemployed or not in the labour force'.

\section{Family level characteristics}

Family level characteristics included household financial stress, experiencing death as a family stressor, or having limited facilities for sanitation in the home.

Financial stress was derived from a single item indicating whether household members could raise \$2000 in an emergency. Respondents who indicated they could not raise $\$ 2000$ were categorised as experiencing 'financial stress'. Death as a family stressor was derived from a single item indicating whether 'death' had occurred in the previous 12 months as a family stressor. Limited facilities for sanitation in the home was derived from a single variable indicating whether respondents' homes had working facilities for washing people, washing clothes or bedding, preparing food, or sewerage facilities. Respondents who indicated that they had no working facilities for any one of these fundamental household tasks were categorised as having 'limited facilities for sanitation at home'. 


\section{Area level characteristics}

Area level characteristics included area level socioeconomic status and geographic remoteness. Area level socioeconomic status was determined from the Index of Relative Socioeconomic Disadvantage developed by the ABS [57]. This index ranks the relative level of disadvantage of areas using the attributes of all persons (Aboriginal and non-Aboriginal) in small areas, and includes measures of income, educational attainment, employment status, family composition, and employment categorisation (i.e. low skill occupations). For the purposes of this study, we have categorised the index values into quintiles. Geographic remoteness was determined according to the Australian Statistical Geographic Standard 2011 remoteness areas with non-remote areas encompassing 'major cities of Australia', 'Inner regional Australia' and 'Outer regional Australia', while remote areas encompassed 'Remote Australia' and 'Very Remote Australia'. Respondents living in remote areas were categorised as 'living in a remote area'.

\section{Covariates}

Age and gender were included as covariates in LCA models. Age was a continuous measure of respondent's age in single years. Gender was categorised as female/ male with male as the reference category.

\section{Data analysis}

Multiple imputation by Chained Equations was conducted in SAS Enterprise Guide 7.15 to minimise potential bias due to missing biomarker data in the NATSIH MS (Additional file 1). The number of respondents with missing data ranged from 14 to $708(0.7-34.4 \%)$ for each biomarker. Descriptive statistics and sample sizes for all biomarkers are included in Supplementary Table 1. Analysis was conducted on the final sample of 2056 respondents after imputation.

Preliminary analysis was run to generate the mean, standard error, and confidence intervals for our index of allostatic load. Percentage distributions of explanatory variables were calculated. Linear regression models, adjusted for age and gender, were used to test associations between each explanatory variable and allostatic load. These analyses were run in SAS Enterprise Guide Version 7.15 .

LCA was used to identify health and psychosocial stress profiles of Aboriginal adults within our sample using the 15 explanatory variables. Statistical model fit was assessed using the Akaike Information Criterion (AIC), sample size adjusted Bayesian Information Criterion (BIC), log-likelihood, and entropy for models with 2-10 classes. After the model of best fit was identified, mean estimates of allostatic load were compared between classes using Bolck, Croon and Hagenaars adjusted proportional assignment to calculate distal outcome estimates $[58,59]$. Finally, racial discrimination exposure was included as a grouping variable in LCA to dichotomise the sample so that mean estimates of allostatic load could be compared between respondents who reported racial discrimination exposure and respondents with no reported racial discrimination exposure within each latent class. Differences in mean allostatic load with exposure to racial discrimination are reported both within and between latent classes in Supplementary Table 2. All LCA was conducted using the LCA Stata Plugin and LCA_Distal_BCH Stata function $[60,61]$ in Stata Version 16.0.

All analysis incorporated the ABS-generated personweights produced for the NATSINPAS dataset. Use of these weights allows us to use sample population data to estimate outcomes for the total in-scope population [47]. All data was accessed and analysis run within the ABS DataLab environment [62].

\section{Results}

Summary statistics of the 2056 participants' responses for the 15 explanatory variables are presented in Table 1; frequencies ranged from $6.8 \%$ (current or pre-existing kidney disease) to $63.7 \%$ (living in a remote area). The sample was comprised of $53.6 \%$ females, with ages ranging from 18 to 75 years $(M=41.5, S D=21.2)$. Means, standard errors, and 75th percentile cut-offs for each of the ten biomarkers comprising the allostatic load risk index are presented in Table 2. The number of biomarkers per individual observed to fall into the high-risk category ranged from 1 to 10 , with a mean of 2.4 (SD: 2.3; 95\% CI: 2.4, 2.5).

Increased age was significantly associated with increased allostatic load $(B=0.1, \mathrm{p}=<.0001)$, while allostatic load

Table 2 Allostatic load outcome variables

\begin{tabular}{|c|c|c|c|c|c|}
\hline Biomarkers & Mean & SD & $95 \% \mathrm{Cl}$ & $P_{75}$ & $\mathbf{N}$ \\
\hline Systolic blood pressure & 121.6 & 18.1 & $120.7-122.4$ & 130.7 & 2056 \\
\hline Diastolic blood pressure & 78.8 & 13.6 & $78.2-79.3$ & 86.0 & 2056 \\
\hline Body mass index & 29.6 & 9.1 & $29.3-29.9$ & 33.9 & 2056 \\
\hline HDL cholesterol & 1.2 & 0.3 & $1.2-1.2$ & $0.9^{b}$ & 2056 \\
\hline LDL cholesterol & 2.9 & 1.4 & $2.9-3.0$ & 3.5 & 2056 \\
\hline Triglycerides & 1.7 & 0.9 & $1.6-1.7$ & 2.1 & 2056 \\
\hline Fasting plasma glucose ${ }^{a}$ & 1.7 & 0.3 & $1.7-1.7$ & 1.8 & 2056 \\
\hline $\mathrm{HbA} 1 \mathrm{c}$ & 5.8 & 1.4 & $5.8-5.9$ & 5.9 & 2056 \\
\hline Albumin creatinine ratio ${ }^{a}$ & 0.2 & 1.4 & $0.1-0.2$ & 0.9 & 2056 \\
\hline C-reactive protein ${ }^{a}$ & 1.1 & 1.4 & $1.1-1.2$ & 2.0 & 2056 \\
\hline Allostatic load & Mean & SD & $95 \% \mathrm{Cl}$ & & $\mathrm{N}$ \\
\hline Allostatic load risk index & 2.4 & 2.3 & $2.3-2.5$ & & 2056 \\
\hline
\end{tabular}


did not differ between male and female participants $(B=$ $0.02, p=.81)$. There were statistically significant differences in mean allostatic load across many of the explanatory variables included in LCA, after adjustment for age and gender (Table 3). The estimated prevalence of racial discrimination exposure within the previous 12 months was $14.6 \%$ (95\% CI: 12.4,16.8). A statistically significant increase in mean allostatic load was observed in participants who reported racial discrimination, after adjustment for age and gender $(B=0.38, p=.02)$ (Table 3$)$.

\section{Latent class analysis}

Fit indices for latent class models with 2 to 10 classes were generated (Table 4). The four-class model was chosen to represent the optimal number of classes based on an appropriate balance between the sample adjusted BIC, entropy, and log-likelihood estimates [46]. Item response probabilities for explanatory variables from the four-class model are presented alongside the probability of latent class membership both for respondents with and without exposure to racial discrimination in Table 5. The four-class model included (1) 'Low risk': characterised by low probabilities of current or pre-existing health conditions, mental health risk indicators, and low probabilities of socioeconomic risk factors; (2) 'Challenged but healthy': characterised by low probabilities of current or pre-existing health conditions, mental health risk indicators, but with moderate probability of experiencing death as a family stressor, and high probabilities of almost all socioeconomic risk factors including financial stress, living in a disadvantaged area, living in a remote area, unemployment, and low education; (3) 'Mental health risk': characterised by a high probability of psychological distress, moderate-high probability of financial stress and unemployment, high probability of a current or pre-existing respiratory condition and low probabilities of all other current or pre-existing health conditions; (4) 'Multiple challenges': characterised by high probabilities of current or pre-existing cardiac, respiratory, and diabetes or related conditions and a relatively high probability of a current or pre-existing kidney condition, moderate probabilities of psychological distress and experiencing death as a family stressor, and moderate-high probabilities of financial stress, low education, unemployment, and living in a disadvantaged area.

\section{Latent classes and allostatic load}

Mean allostatic load for each latent class was estimated after including the allostatic load risk index as a distal outcome in LCA in a model adjusted for age and gender (Table 5). Mean allostatic load was observed to vary significantly by latent class $(Z=301.7, \mathrm{p}=<.001)$ (Table 6). The 'Multiple challenges' class was observed to have the highest mean allostatic load (4.05; 95\% CI: 3.84, 4.26). This estimate was significantly higher than mean estimates for all other classes, while the estimate for the 'Challenged but healthy' class was significantly higher than the 'Low risk' $(B=0.44, \mathrm{SE}=0.07, \mathrm{p}=<.0001)$ and 'Mental health risk' $(B=0.39, \mathrm{SE}=0.09, \mathrm{p}=<.0001)$ classes. No significant difference in allostatic load was observed between the 'Low risk' and 'Mental health risk' classes.

\section{Latent classes, allostatic load and racial discrimination}

Mean allostatic load for each latent class was again estimated in an extended latent class model that dichotomised respondents into those exposed and unexposed to racial discrimination in the previous 12 months before including the allostatic load index as a distal outcome (Table 5). This permitted mean allostatic load to be estimated in each latent class both for individuals with and without exposure to racial discrimination in the previous 12 months. Mean allostatic load varied significantly between latent classes both for those with $(Z=67.5, \mathrm{p}=$ $<.001)$ and those without exposure to racial discrimination $(Z=235.5, \mathrm{p}=<.001)$ (Table 6).

Mean estimated allostatic load was significantly higher for those in the 'Multiple challenges' class with exposure to racial discrimination compared to those unexposed $(t=1.74, p=.04)$, while allostatic load was significantly lower for those in the 'Mental health risk' class with exposure to racial discrimination compared to those unexposed $(t=-1.67, p=.05) \quad$ (Table 7). The 'Multiple challenges' class was observed to have the highest mean allostatic load compared with all other classes both for those with exposure to racial discrimination in the previous 12 months $(4.48 ; 95 \% \mathrm{CI}: 3.95,5.00)$ and for those unexposed (3.95; 95\% CI: 3.73, 4.18).

\section{Discussion}

This study presents a first exploration of how patterns of psychosocial stressors, environmental and mental health factors, and health conditions within latent classes affect multisystem dysregulation in a First Nations population. We used LCA with distal outcomes to identify profiles of Aboriginal Australian adults defined by these factors, examine the association between these profiles and an index of allostatic load, and determine whether the association between latent classes and allostatic load differed for those exposed and unexposed to racial discrimination.

Our study observed that allostatic load was significantly increased for individuals with exposure to racial discrimination in the 'Multiple challenges' class compared to those unexposed to racial discrimination in this class. By contrast, allostatic load was significantly lower for those exposed to racial discrimination in the 'Mental health risk' class compared to those unexposed. No significant difference in allostatic load was observed between those exposed and unexposed to racial discrimination in 
Table 3 Mean allostatic load by explanatory variables

Explanatory variables

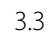

No

3.3

2.4

Current or pre-existing cardiac condition

Yes $\quad 3.1$

Current or pre-existing diabetes or related condition

$\begin{array}{ll}\text { Yes } & 3.6 \\ \text { No } & 1.9\end{array}$

Current or pre-existing respiratory condition

$\begin{array}{ll}\text { Yes } & 2.5 \\ \text { No } & 2.4\end{array}$

Psychological distress

$\begin{array}{ll}\text { Yes } & 2.4 \\ \text { No } & 2.5\end{array}$

Low social support

Yes

No

Low sense of control

Yes

No

2.1

Did not meet exercise guidelines

$\begin{array}{ll}\text { Yes } & 2.3 \\ \text { No } & 2.0\end{array}$

Completed Year 11 or below

$\begin{array}{ll}\text { Yes } & 2.8 \\ \text { No } & 2.1\end{array}$

Unemployed or not in the labour force

$\begin{array}{ll}\text { Yes } & 2.7 \\ \text { No } & 2.1\end{array}$

Financial stress

$\begin{array}{ll}\text { Yes } & 2.7\end{array}$

No

Family stressor - Death

$\begin{array}{ll}\text { Yes } & 2.7 \\ \text { No } & 2.0\end{array}$

Limited facilities for sanitation at home
Mean

\section{SE}

0.2

0.1

3.1

0.1

6.1

0.1

0.1

0.1

0.1

0.2

0.2

0.1

\section{1}

0.1

0.1

0.1

0.1

0.1

0.1

0.1
B $^{a}$

0.39

Ref

0.53

Ref

1.19

Ref

$-0.09$

Ref

$-0.02$

Ref

0.09

Ref

0.32

Ref

0.16

Ref

0.45

Ref

0.43

Ref

0.77

Ref

No

.

ef

.

.

09

32

ef

\section{6}

Ref

Ref

43

Index of Relative Socioeconomic Advantage and Disadvantage

$\begin{array}{ll}1 \text { - Most disadvantaged } & 2.6 \\ 2 & 2.6 \\ 3 & 2.3 \\ 4 & 2.2\end{array}$

0.1

0.1

0.2

0.2

$95 \% \mathrm{Cl}$

$0.03-0.74$

19

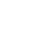

0.09

0.02

45


Table 3 Mean allostatic load by explanatory variables (Continued)

\begin{tabular}{|c|c|c|c|c|c|}
\hline Explanatory variables & Mean & SE & $\mathrm{B}^{\mathrm{a}}$ & $95 \% \mathrm{Cl}$ & $P$-value \\
\hline 5 - Least disadvantaged & 1.3 & 0.2 & Ref & $\ldots$ & $\ldots$ \\
\hline \multicolumn{6}{|l|}{ Living in a remote area } \\
\hline Yes & 2.9 & 0.1 & 0.90 & $0.72-1.07$ & $<.0001$ \\
\hline No & 2.2 & 0.1 & Ref & $\ldots$ & $\ldots$ \\
\hline \multicolumn{6}{|c|}{ Racial discrimination exposure previous 12 months } \\
\hline Yes & 2.7 & 0.1 & 0.28 & $0.04-0.51$ & 0.02 \\
\hline No & 2.4 & 0.1 & Ref & $\ldots$ & $\ldots$ \\
\hline
\end{tabular}

${ }^{\mathrm{a}}$ Beta estimates indicate group differences in mean allostatic load

other latent classes. The 'Multiple challenges' class was characterised by high proportions of individuals who reported experiencing death as a family stressor, financial stress, unemployment, and low education, alongside current or pre-existing diabetes and cardiac conditions. Overall, our results indicate that racial discrimination can measurably increase allostatic load for groups of Aboriginal adults with this profile of psychosocial stress and health vulnerability, suggesting that these individuals were still physiologically susceptible to the additional psychosocial stressor of racism.

This study confirms that while exposure to racial discrimination has an effect on the physiological dysregulation linked with allostatic load, this effect is significant only in select contexts. Allostatic load was significantly increased between those exposed and unexposed to racial discrimination within the 'Multiple challenges' class, significantly decreased between those exposed and unexposed to racial discrimination within the 'Mental health risk' class, and no significant differences were observed between those exposed and unexposed in the remaining classes. Multiple individual stressors were significantly associated with increased allostatic load after adjustment for age and gender, providing an indication of the variety of psychosocial stressors that can affect allostatic load. Overall, results from these analyses suggest that not all circumstances in which Aboriginal people live lend themselves to an increased vulnerability from the adverse physiological effects of racism. These findings underscore that we cannot easily summarise the broader circumstances of Aboriginal peoples' lives or the continuing adaption of those lives to the adversities often present within them. Racial discrimination is frequently numbered among these adversities, yet when examining the impact of racism on physiological health it is worth broadening the scope of analysis to include, rather than adjust for, socioecological, environmental, and health factors. This is especially the case where these factors have the potential to moderate the body's physiological response to stress.

Findings from this study show that Aboriginal adults living in high stress environments with low socioeconomic resources have a higher allostatic load than those living in a low stress environment with high socioeconomic resources. This is the case even in the absence of reported health conditions and psychological distress. Respondents in the 'Challenged but healthy' class were observed to have a significantly higher allostatic load than respondents in the 'Low risk' class in the total sample, both before and after grouping for racial discrimination exposure. Both class profiles indicated low proportions of those with pre-existing health conditions

Table 4 Fit indices for one to ten latent class models

\begin{tabular}{llllll}
\hline Number of classes & Log-likelihood & AIC & BIC (sample size adjusted) & Change in BIC & Entropy \\
\hline 1 & $-17,394$ & 7715 & 7759 & -1629 & -2.06 \\
2 & $-16,537$ & 6039 & 6130 & -471 & 0.73 \\
3 & $-16,259$ & 5522 & 5659 & -151 & 0.70 \\
4 & $-16,141$ & 5324 & 5508 & -40 & 0.70 \\
5 & $-16,079$ & 5237 & 5468 & -12 & 0.70 \\
6 & $-16,031$ & 5179 & 5456 & -7 & 0.68 \\
7 & $-15,985$ & 5126 & 5449 & +15 & 0.68 \\
8 & $-15,950$ & 5093 & 5464 & +44 & 0.70 \\
10 & $-15,930$ & 5091 & 5508 & 50 & 0.71 \\
\hline
\end{tabular}


Table 5 Latent class membership, item response probabilities, and mean allostatic load estimates by latent class and racial discrimination exposure

\begin{tabular}{|c|c|c|c|c|}
\hline Latent class membership probabilities & Low risk & Challenged but healthy & Mental health risk & Multiple challenges \\
\hline Racial discrimination exposure & 0.220 & 0.188 & 0.231 & 0.362 \\
\hline No racial discrimination exposure & 0.308 & 0.278 & 0.174 & 0.240 \\
\hline \multicolumn{5}{|l|}{ Item response probabilities } \\
\hline Current or pre-existing diabetes or related condition & 0.189 & 0.138 & 0.142 & 0.770 \\
\hline Current or pre-existing cardiac condition & 0.258 & 0.179 & 0.311 & 0.861 \\
\hline Current or pre-existing respiratory condition & 0.459 & 0.159 & 0.686 & 0.594 \\
\hline Current or pre-existing kidney condition & 0.020 & 0.027 & 0.033 & 0.188 \\
\hline Psychological distress & 0.096 & 0.248 & 0.655 & 0.357 \\
\hline Low social support & 0.005 & 0.199 & 0.210 & 0.211 \\
\hline Low sense of control & 0.000 & 0.000 & 0.237 & 0.147 \\
\hline Did not meet exercise guidelines & 0.448 & 0.560 & 0.388 & 0.594 \\
\hline Family stressor - Death & 0.459 & 0.674 & 0.519 & 0.630 \\
\hline Financial stress & 0.157 & 0.875 & 0.678 & 0.586 \\
\hline Limited facilities for sanitation at home & 0.020 & 0.464 & 0.152 & 0.208 \\
\hline Completed Year 11 or below & 0.265 & 0.697 & 0.485 & 0.624 \\
\hline Unemployed or not in the labour force & 0.109 & 0.711 & 0.733 & 0.740 \\
\hline Living in area of relative disadvantage & 0.279 & 0.918 & 0.443 & 0.539 \\
\hline Living in a remote area & 0.121 & 0.900 & 0.052 & 0.303 \\
\hline Mean allostatic load & \multicolumn{4}{|c|}{ Estimate (95\% Confidence Intervals) } \\
\hline Full sample $(n=2056)$ & $1.67(1.49,1.85)$ & $2.58(2.41,2.74)$ & $1.75(1.45,2.04)$ & $4.05(3.84,4.26)$ \\
\hline Racial discrimination exposure $(n=292)$ & $1.88(1.35,2.41)$ & $2.85(1.83,2.74)$ & $1.20(0.61,1.79)$ & $4.48(3.95,5.00)$ \\
\hline No racial discrimination exposure $(n=1764)$ & $1.64(1.45,1.83)$ & $2.67(2.49,2.85)$ & $1.78(1.46,2.11)$ & $3.95(3.73,4.18)$ \\
\hline
\end{tabular}

or psychological distress, although the 'Challenged but healthy' class had considerably higher proportions of respondents indicating financial stress, unemployment, low education, and area-level disadvantage compared to the 'Low risk' class. Our findings suggest that the financial stress and resource deprivation related to low socioeconomic status (SES) contributes to a higher allostatic load burden in Aboriginal adults with otherwise positive physical and mental health profiles. Strong and consistent associations between lower SES and allostatic load have been empirically established [29, 63] and various mediators of the association between SES and allostatic load have been identified [32]. Economic difficulties encountered during adulthood have also been observed to amplify allostatic load in those exposed to stressors during childhood and adolescence, suggesting that SES can have an additive effect where maladaptive physiologic patterns have already been established [64]. Mechanisms like this illustrate how allostatic load can be indicative of past stress, providing a marker of the cumulative physiological toll exacted on the body over time. These observations suggest that allostatic load provides both an indication of past challenges and a risk factor for future physiological response patterns [29]. Where individuals have faced many stressors or challenging environments in the past, these patterns are more likely to be physiologically damaging and disease-promoting [65]. Based on results from this study, it appears that SES-related determinants can contribute to increases in physiological dysregulation for Aboriginal adults and that measures of SES must be accounted for when examining allostatic load in this population.

Levels of allostatic load were significantly lower for respondents characterised by indicators of psychological distress ('Mental health risk') compared to respondents characterised by low SES ('Challenged but healthy'). In fact, levels of allostatic load for those in the 'Mental health risk' class were comparable to those observed in the 'Low risk' class. Additionally, those in the 'Mental health risk' class with exposure to racial discrimination were observed to have significantly lower allostatic load compared to those who were unexposed. These findings suggest that the components of adverse mental health incorporated into LCA models did not completely explain an observable increase in allostatic load and that exposure to racial discrimination interacts with mental health to measurably reduce allostatic load. Strong evidence for a link between allostatic load and adverse 
Table 6 Wald chi-squared tests, allostatic load risk index

\begin{tabular}{|c|c|c|c|c|c|}
\hline \multicolumn{2}{|l|}{ Full Sample } & \multirow{2}{*}{$\begin{array}{l}\text { Estimate } \\
-0.436\end{array}$} & \multirow{2}{*}{$\frac{\text { SE }}{0.065}$} & \multirow{2}{*}{$\begin{array}{l}\text { Wald statistic } \\
44.939\end{array}$} & \multirow{2}{*}{$\frac{\text { P-value }}{<.001}$} \\
\hline Low risk & Challenged but healthy & & & & \\
\hline Low risk & Mental health risk & -0.048 & 0.109 & 0.192 & ns \\
\hline Low risk & Multiple challenges & -0.888 & 0.062 & 206.248 & $<.001$ \\
\hline Challenged but healthy & Mental health risk & 0.388 & 0.094 & 16.913 & $<.001$ \\
\hline Challenged but healthy & Multiple challenges & -0.453 & 0.0439 & 106.449 & $<.001$ \\
\hline \multirow[t]{2}{*}{ Mental health risk } & Multiple challenges & -0.841 & 0.093 & 82.170 & $<.001$ \\
\hline & Omnibus test & & & 301.737 & $<.001$ \\
\hline \multicolumn{6}{|c|}{ Racial discrimination exposure } \\
\hline Low risk & Challenged but healthy & -0.196 & 0.181 & 1.176 & ns \\
\hline Low risk & Mental health risk & 0.447 & 0.306 & 2.136 & ns \\
\hline Low risk & Multiple challenges & -0.869 & 0.161 & 29.121 & $<.001$ \\
\hline Challenged but healthy & Mental health risk & 0.644 & 0.281 & 5.246 & $<.025$ \\
\hline Challenged but healthy & Multiple challenges & -0.673 & 0.124 & 29.442 & $<.001$ \\
\hline \multirow[t]{2}{*}{ Mental health risk } & Multiple challenges & -1.317 & 0.266 & 24.518 & $<.001$ \\
\hline & Omnibus test & & & 67.507 & $<.001$ \\
\hline \multicolumn{6}{|c|}{ No racial discrimination exposure } \\
\hline Low risk & Challenged but healthy & -0.488 & 0.069 & 50.119 & $<.001$ \\
\hline Low risk & Mental health risk & -0.085 & 0.119 & 0.515 & ns \\
\hline Low risk & Multiple challenges & -0.881 & 0.067 & 173.425 & $<.001$ \\
\hline Challenged but healthy & Mental health risk & 0.402 & 0.103 & 15.315 & $<.001$ \\
\hline Challenged but healthy & Multiple challenges & -0.393 & 0.0469 & 70.174 & $<.001$ \\
\hline \multirow[t]{2}{*}{ Mental health risk } & Multiple challenges & -0.795 & 0.102 & 61.179 & $<.001$ \\
\hline & Omnibus test & & & 235.537 & $<.001$ \\
\hline
\end{tabular}

mental health has been observed in international studies and allostatic load has been proposed as a likely predicter of adverse mental health in Aboriginal populations $[19,66,67]$. Currently, further research is required to fully determine the association between increased allostatic load and adverse mental health in Aboriginal Australian populations. Cortisol and cortisone levels measured from hair samples of Aboriginal young adults were not significantly associated with psychological distress in the Aboriginal Birth Cohort Study, [68] while no significant association was observed between an allostatic load index comprised of multiple biomarkers and depressive symptoms in recent research undertaken with Aboriginal adolescents and adults in Queensland, Australia [69]. However, the Queensland study observed that anhedonia and insomnia sub-scores were significantly associated with increased allostatic load in one of the study sites, suggesting that depression symptomology can influence allostatic load [69]. Our observation that psychological distress and low sense of control are not significantly associated with allostatic load in regression analysis adjusted for age and gender suggests a less marked association with these mental health symptoms. However, the implications of our observation that allostatic load is lower for those with a high mental health risk profile who report exposure to racial discrimination are less clear. Emerging evidence from Aboriginal populations indicates that chronic exposure to psychosocial stressors can lead to suppression of the hypothalamicpituitary-adrenal (HPA) axis measured via lower cortisol,

Table 7 Mean difference between those exposed and unexposed to racial discrimination, within latent classes

\begin{tabular}{|c|c|c|c|c|}
\hline & Mean difference - exposed compared with unexposed & SE of difference between means & T statistic & P-value \\
\hline Low risk & 0.239 & 0.293 & 0.82 & 0.206 \\
\hline Challenged but healthy & -0.383 & 0.240 & -1.47 & 0.072 \\
\hline Mental health risk & -0.585 & 0.350 & -1.67 & 0.048 \\
\hline Multiple challenges & 0.524 & 0.300 & 1.74 & 0.041 \\
\hline
\end{tabular}


cortisone, and a blunted cortisol awakening response $[24,68,70]$. Although a broader set of biomarkers were incorporated into our allostatic load index, the combination of stressors present within our mental health risk profile in addition to racial discrimination exposure may be indicative of this type of physiological response.

The strengths of this study include the novel investigation of allostatic load, racial discrimination and psychosocial, environmental and health factors in a large nationally representative sample of Australian Aboriginal adults. As allostatic load is conceptualised as an indicator of the cumulative effects of stress and adversity, our study design ensured that a broad range of factors were accounted for when examining the link between racial discrimination and this measure of physiological dysregulation. Alongside these strengths, our study encountered some limitations. First, our study was crosssectional and could not account for interactions between racial discrimination, psychosocial, environmental and health factors, and allostatic load over time. We are unable to determine whether exposure to racial discrimination had occurred prior to the previous 12 months, or the frequency and duration of this exposure. Neither are we able to determine the temporal sequence of many explanatory variables included in LCA, racial discrimination exposure and the development of physiological dysregulation captured by the index of allostatic load. Second, a critical component within the literature on life and environmental stress concerns perceptions of stress [71]. Respondents in this study were unable to indicate the presence or degree of stress they perceived in response to individual measures included as explanatory factors in LCA. Third, the measure of racial discrimination utilised in this study was a single-item measure that has not been methodologically validated. Racism is a complex phenomenon and multi-item measures have been shown to be more reliable and able to capture this complexity [72]. Validated, multi-item racial discrimination measures have been developed for Aboriginal populations (e.g. the Measure of Indigenous Racism Experiences) [73] and would more accurately reflect the experience of racism for these populations. Fourth, although the biomedical data collected in this study over 2012-13 represents the most recent and comprehensive available in a nationally representative Aboriginal population dataset, these data are now several years old. Despite this, there have been few significant changes in the social, economic, and health circumstances of Aboriginal children and families across Australia since the AATS IHS data were collected. Accordingly, we strongly believe the data continue to be a relevant and useful resource for examination of the circumstances of Aboriginal and Torres Strait Islander peoples. Finally, many individual biomarkers included in the allostatic load index used within this study are predictive of the current or previous health conditions reported by respondents that were used in latent class formation. For those in the 'Multiple challenges' class, levels of allostatic load are likely primarily driven by the high proportion of respondents reporting the presence of these conditions.

\section{Conclusions}

We observed that allostatic load was significantly increased for those exposed to the psychosocial stressor of racism in a profile of Aboriginal adults already experiencing multiple challenges and adverse health. Our findings also indirectly imply that Aboriginal individuals with fewer challenges, greater resources, or differing life circumstances (e.g. living in a remote area) were more physiologically resilient to the additional stressor of racial discrimination. This finding does nothing to diminish the importance of responding to racial discrimination as a social determinant of health, rather it highlights that the specific conditions of Aboriginal people's lives must be accounted for when attempting to understand the link between racism and physiological health. The harmful effects of racism on Aboriginal health are modifiable and a stronger understanding of the circumstances in which they occur can encourage the development of evidence-based prevention strategies to mitigate their onset and continuation. Prevention strategies may take the form of intervention programs with linked evaluations or policy approaches which cut across multiple systems (e.g. healthcare, education, housing) to address the impact of racism on national health disparities.

\section{Supplementary Information}

The online version contains supplementary material available at https://doi. org/10.1186/s12889-020-09978-7.

Additional file 1. Detailed description of multiple imputation.

Additional file 2. STROBE statement. Checklist of reporting guidelines for observational studies (cross-sectional).

Additional file 3: Table S1. Complete cases and imputed values for individual biomarkers and allostatic load risk index.

Additional file 4: Table S2. Mean difference in allostatic load between those exposed and unexposed to racial discrimination, within and between class comparisons.

\section{Abbreviations \\ AIC: Akaike Information Criterion; ACR: Albumin-creatinine ratio; AATS IHS: Australian Aboriginal and Torres Strait Islander Health Survey; ABS: Australian Bureau of Statistics; BIC: Bayesian Information Criterion; $\mathrm{Cl}$ : Confidence interval; HDL: High density lipoprotein; Kessler-5: Kessler Psychological Distress Scale; LCA: Latent class analysis; LDL: Low density lipoprotein; MSPSS: Multidimensional Scale of Perceived Social Support; NATS IHMS: National Aboriginal and Torres Strait Islander Health Measures Survey; NATSIHS: National Aboriginal and Torres Strait Islander Health Survey; HbA1c: Plasma glycosylated haemoglobin; SE: Standard error; SD: Standard deviation}

\section{Acknowledgements}

We gratefully acknowledge the advice and guidance provided by members of the Telethon Kids Institute Social Determinants of Aboriginal Health 
Community Advisory Group: Emma Castle, Jayde Conway, Doris Getta, Janet Hansen, Raelene Hayward, Justin Kickett, Lakkiera Miller, Ralph Mogridge, Doreen Nelson, and Fred Penny. We wish to thank the Australian Bureau of Statistics for providing access to this dataset and to acknowledge the contribution of the Aboriginal and Torres Strait Islander men and women who participated in the AATSIHS and made this work possible.

\section{Authors' contributions}

LC conceived of and designed the study. LC conducted the primary statistical analysis and imputation analysis. CCJS, LC, MNC, and SRZ interpreted the data. LC wrote the initial drafts of the manuscript. All authors have read, revised and approved the final manuscript.

\section{Funding}

This work was supported by an Australian Government Research Training Program Scholarship and the Australian Research Council's Centre of Excellence for Children and Families over the Life Course (Project ID 140100027). The funding bodies had no role in the design of the study, data collection, analysis, interpretation of data or in writing the manuscript.

\section{Availability of data and materials}

The data that support the findings of this study are available from the Australian Bureau of Statistics but restrictions apply to the availability of these data, which were used under license for the current study, and so are not publicly available. Data are however available from the authors upon reasonable request and with permission of the Australian Bureau of Statistics.

\section{Ethics approval and consent to participate}

Ethics approval for this study was granted by the Western Australian Aboriginal Health Ethics Committee (809) and the University of Western Australia Human Research Ethics Committee (RA/4/20/4069). Written consent for the Australian Aboriginal and Torres Strait Islander Health Survey was provided to the Australian Bureau of Statistics.

\section{Consent for publication}

Not applicable.

\section{Competing interests}

The authors declare that they have no competing interests.

\section{Author details}

'Telethon Kids Institute, The University of Western Australia, PO Box 855, West Perth, Western Australia 6872, Australia. ${ }^{2}$ School of Population and Global Health, The University of Western Australia, 35 Stirling Highway, Perth, Western Australia 6009, Australia. ${ }^{3}$ Centre for Child Health Research, The University of Western Australia, 35 Stirling Highway, Perth, Western Australia 6009, Australia. ${ }^{4}$ Ngangk Yira Research Centre for Aboriginal Health \& Social Equity, Murdoch University, 90 South Street, Murdoch, Western Australia 6150, Australia.

Received: 25 May 2020 Accepted: 26 November 2020

Published online: 07 December 2020

\section{References}

1. Williams DR. Race, Socioeconomic Status, and Health The Added Effects of Racism and Discrimination. In: Adler N, Marmot M, McEwen B, Stewart J, editors. Socioeconomic Status and Health in Industrial Nations: Social, Psychological, and Biological Pathways. 896. New York: New York Academy of Sciences; 1999. p. 173-88.

2. Pascoe EA, Richman LS. Perceived discrimination and health: a meta-analytic review. Psychol Bull. 2009;135(4):531-54.

3. Paradies Y, Ben J, Denson N, Elias A, Priest N, Pieterse A, et al. Racism as a determinant of health: a systematic review and meta-analysis. PLoS One. 2015;10(9):e0138511.

4. Priest N, Paradies Y, Trenerry B, Truong M, Karlsen S, Kelly Y. A systematic review of studies examining the relationship between reported racism and health and wellbeing for children and young people. Soc Sci Med. 2013. 95(0):115-27.

5. Williams DR, Lawrence JA, Davis BA. Racism and health: evidence and needed research. Annu Rev Public Health. 2019;40(1):105-25.
6. Williams DR, Lawrence JA, Davis BA, Vu C. Understanding how discrimination can affect health. Health Serv Res. 2019;54(Suppl 2):1374-88.

7. Paradies Y. Colonisation, racism and indigenous health. J Popul Res. 2016; 33(1):83-96.

8. Temple JB, Kelaher M, Paradies Y. Prevalence and context of racism experienced by older Aboriginal and Torres Strait islanders. Australas J Ageing. 2019;38(1):39-46.

9. Cunningham J, Paradies Y. Patterns and correlates of self-reported racial discrimination among Australian Aboriginal and Torres Strait Islander adults, 2008-09: Analysis of national survey data. Int J Equity Health. 2013;12(1):1-15.

10. Bodkin-Andrews G, Carlson B. The legacy of racism and indigenous Australian identity within education. Race Ethn Educ. 2016;19(4):784-807.

11. Paradies $Y$, Cunningham J. The DRUID study: racism and self-assessed health status in an indigenous population. BMC Public Health. 2012;12(1):131.

12. Priest $N$, Paradies $Y$, Stewart $P$, Luke J. Racism and health among urban Aboriginal young people. BMC Public Health. 2011;11(1):568.

13. Priest N, Paradies $Y$, Stevens $M$, Bailie R. Exploring relationships between racism, housing and child illness in remote indigenous communities. J Epidemiol Community Health. 2010;66(5):440-7.

14. Larson A, Gillies M, Howard PJ, Coffin J. It's enough to make you sick: the impact of racism on the health of Aboriginal Australians. Aust N Z J Public Health. 2007:31(4):322-9.

15. Shepherd CCJ, Li J, Cooper MN, Hopkins KD, Farrant BM. The impact of racial discrimination on the health of Australian indigenous children aged 5-10 years: analysis of national longitudinal data. Int J Equity Health. 2017; 16(1):116.

16. Cave L, Cooper MN, Zubrick SR, Shepherd CCJ. Caregiver-perceived racial discrimination is associated with diverse mental health outcomes in Aboriginal and Torres Strait islander children aged 7-12 years. Int J Equity Health. 2019;18(1):142

17. Burgard SA, Chen PV. Challenges of health measurement in studies of health disparities. Soc Sci Med. 2014;106:143-50.

18. Dowd JB, Zajacova A. Does self-rated health mean the same thing across socioeconomic groups? Evidence from biomarker data. Ann Epidemiol. 2010;20(10):743-9.

19. Sarnyai Z, Berger M, Jawan I. Allostatic load mediates the impact of stress and trauma on physical and mental health in indigenous Australians. Aust Psychiatry. 2016:24(1):72-5.

20. Priest N, Paradies Y, Gunthorpe W, Cairney SJ, Sayers SM. Racism as a determinant of social and emotional wellbeing for Aboriginal Australian youth. Med J Aust. 2011;194(10):546-50.

21. Ben J, Paradies Y, Priest N, Parker EJ, Roberts-Thomson KF, Lawrence HP, et al. Self-reported racism and experience of toothache among pregnant Aboriginal Australians: the role of perceived stress, sense of control, and social support. J Public Health Dent. 2014;74(4):301-9.

22. Jamieson LM, Paradies YC, Gunthorpe W, Cairney SJ, Sayers SM. Oral health and social and emotional well-being in a birth cohort of Aboriginal Australian young adults. BMC Public Health. 2011;11:11.

23. Brown SJ, Gartland D, Weetra D, Leane C, Francis T, Mitchell A, et al. Health care experiences and birth outcomes: results of an Aboriginal birth cohort. Women Birth. 2019;32(5):404-11.

24. Berger M, Leicht A, Slatcher A, Kraeuter AK, Ketheesan S, Larkins S, et al. Cortisol awakening response and acute stress reactivity in first nations people. Sci Rep. 2017;7:41760.

25. McEwen BS. Stress, adaptation, and disease: Allostasis and Allostatic load. Ann N Y Acad Sci. 1998;840(1):33-44.

26. Berger M, Sarnyai Z. "More than skin deep": stress neurobiology and mental health consequences of racial discrimination. Stress. 2015;18(1):1.

27. Juster RP, McEwen BS, Lupien SJ. Allostatic load biomarkers of chronic stress and impact on health and cognition. Neurosci Biobehav Rev. 2010;35(1):2-16.

28. Dowd JB, Simanek AM, Aiello AE. Socio-economic status, cortisol and allostatic load: a review of the literature. Int J Epidemiol. 2009;38(5):1297-309.

29. Seeman T, Epel E, Gruenewald T, Karlamangla A, McEwen BS. Socioeconomic differentials in peripheral biology: cumulative allostatic load. Ann N Y Acad Sci. 2010;1186(1):223-39.

30. Worthman CM, Panter-Brick C. Homeless street children in Nepal: use of allostatic load to assess the burden of childhood adversity. Dev Psychopathol. 2008;20(1):233-55.

31. Slopen N, Non A, Williams DR, Roberts AL, Albert MA. Childhood adversity, adult neighborhood context, and cumulative biological risk for chronic diseases in adulthood. Psychosom Med. 2014;76(7):481-9. 
32. Upchurch DM, Stein J, Greendale GA, Chyu L, Tseng C-H, Huang M-H, et al. A longitudinal investigation of race, socioeconomic Status, and psychosocial mediators of Allostatic load in midlife women: findings from the study of Women's health across the nation. Psychosom Med. 2015;77(4):402-12.

33. Tomfohr LM, Pung MA, Dimsdale JE. Mediators of the relationship between race and allostatic load in African and white Americans. Health Psychol. 2016;35(4):322-32.

34. Zilioli S, Imami L, Ong AD, Lumley MA, Gruenewald T. Discrimination and anger control as pathways linking socioeconomic disadvantage to allostatic load in midlife. J Psychosom Res. 2017;103:83-90.

35. Allen AM, Thomas MD, Michaels EK, Reeves AN, Okoye U, Price MM, et al. Racial discrimination, educational attainment, and biological dysregulation among midlife African American women. Psychoneuroendocrinology. 2019; 99:225-35.

36. Allen AM, Wang Y, Chae DH, Price MM, Powell W, Steed TC, et al. Racial discrimination, the superwoman schema, and allostatic load: exploring an integrative stress-coping model among African American women. Ann N Y Acad Sci. 2019;1457(1):104-27.

37. Brody GH, Lei MK, Chae DH, Yu T, Kogan SM, Beach SR. Perceived discrimination among African American adolescents and allostatic load: a longitudinal analysis with buffering effects. Child Dev. 2014;85(3):989-1002

38. Cuevas AG, Wang K, Williams DR, Mattei J, Tucker KL, Falcon LM. The association between perceived discrimination and allostatic load in the Boston Puerto Rican Health Study. Psychosom Med. 2019;81(7):1-15

39. Currie CL, Copeland $J$, Metz GA. Childhood racial discrimination and adult allostatic load: the role of indigenous cultural continuity in allostatic resiliency. Soc Sci Med. 2019;241:112564.

40. Currie CL, Copeland JL, Metz GA, Chief Moon-Riley K, Davies CM. Past-year racial discrimination and Allostatic load among indigenous adults in Canada: the role of cultural continuity. Psychosom Med. 2020;82(1):99-107.

41. Ong AD, Williams DR, Nwizu U, Gruenewald TL. Everyday unfair treatment and multisystem biological dysregulation in African American adults. Cultur Divers Ethnic Minor Psychol. 2017;23(1):27-35.

42. Thomas MD, Michaels EK, Reeves AN, Okoye U, Price MM, Hasson RE, et al. Differential associations between everyday versus institution-specific racial discrimination, self-reported health, and allostatic load among black women: implications for clinical assessment and epidemiologic studies. Ann Epidemiol. 2019;35:20-8.e3.

43. Tian $Y$, Ming $H$, Huang $S$, Zhang $H$. Discrimination increases the association between parental and adolescent Allostatic load in Chinese rural-to-urban migrants. J Adolesc Health. 2020;66(4):499-505.

44. Van Dyke ME, Baumhofer NK, Slopen N, Mujahid MS, Clark CR, Williams DR, et al. Pervasive discrimination and Allostatic load in African American and white adults. Psychosom Med. 2020;82(3):316-23.

45. Geronimus AT, Hicken M, Keene D, Bound J. "Weathering" and age patterns of allostatic load scores among blacks and whites in the United States. Am J Public Health. 2006;96(5):826.

46. Muthen B, Muthen LK. Integrating person-centered and variable-centered analyses: growth mixture modeling with latent trajectory classes. Alcohol Clin Exp Res. 2000;24(6):882-91

47. Australian Bureau of Statistics. Australian Aboriginal and Torres Strait Islander Health Survey: Users' Guide 2013 [Available from: https://www.abs gov.au/AUSSTATS/abs@.nsf/Lookup/4727.0.55.002Main+Features12012-13 ?OpenDocument.

48. Calabria B, Korda RJ, Lovett RW, Fernando P, Martin T, Malamoo L, et al. Absolute cardiovascular disease risk and lipid-lowering therapy among Aboriginal and Torres Strait islander Australians. Med J Aust. 2018;209(1):35-41.

49. Jelfs PL. The Australian Bureau of Statistics' Aboriginal and Torres Strait islander enumeration and engagement strategies: challenges and future options. In: Kukutai T, Taylor J, editors. Indigenous data sovereignty : toward an agenda. Research monograph (Australian National University. Centre for Aboriginal Economic Policy Research) no. 38. Acton, ACT: ANU Press; 2016.

50. Australian Bureau of Statistics. ABS Reconciliation Action Plan, 2018-21 2018 [Available from: https://www.abs.gov.au/ausstats/abs@.nsf/Lookup/1011. Omain+features12018-21

51. Johnson SC, Cavallaro FL, Leon DA. A systematic review of allostatic load in relation to socioeconomic position: poor fidelity and major inconsistencies in biomarkers employed. Soc Sci Med. 2017;192:66-73.

52. Stewart JA. The detrimental effects of allostasis: allostatic load as a measure of cumulative stress. J Physiol Anthropol. 2006;25(1):133-45.
53. Andrews $\mathrm{G}$, Slade T. Interpreting scores on the Kessler psychological distress scale (K10). Aust N Z J Public Health. 2001;25(6):494-7.

54. Australian Institute of Health and Welfare. Measuring the social and emotional wellbeing of Aboriginal and Torres Strait islander peoples. Canberra: AlHW; 2009 .

55. Zimet GD, Dahlem NW, Zimet SG, Farley GK. The multidimensional scale of perceived social support. J Pers Assess. 1988;52(1):30-41.

56. Pearlin LI, Schooler C. The structure of coping. J Health Soc Behav. 1978; 19(1):2-21.

57. Australian Bureau of Statistics. Census of Population and Housing: SocioEconomic Indexes for Areas (SEIFA), Australia, 20112013 [Available from: https://www.abs.gov.au/AUSSTATS/abs@.nsf/Lookup/2033.0.55.001Main+ Features12011?OpenDocument.

58. Bolck A, Croon M, Hagenaars J. Estimating latent structure models with categorical variables: one-step versus three-step estimators. Polit Anal. 2004; 12(1):3-27.

59. Lanza ST, Tan X, Bray BC. Latent class analysis with distal outcomes: a flexible model-based approach. Struct Equ Model Multidiscip J. 2013;20(1): $1-26$.

60. [Software]. LCA Distal BCH Stata Function (Version 1.1). University Park: The Methodology Center, Penn State 2017.

61. LCA Stata Plugin (Version 1.2). University Park: The Methodology Center, Penn State. 2015.

62. Parker T. The DataLab of the Australian Bureau of Statistics. Australian Economic Review. 2017;50(4):478-83.

63. Beckie TM. A systematic review of allostatic load, health, and health disparities. Biol Res Nurs. 2012;14(4):311-46.

64. Berg MT, Simons RL, Barr A, Beach SRH, Philibert RA. Childhood/adolescent stressors and allostatic load in adulthood: support for a calibration model. Soc Sci Med. 2017;193:130-9.

65. McEwen BS, Seeman T. Protective and damaging effects of mediators of stress: elaborating and testing the concepts of Allostasis and Allostatic load. Ann N Y Acad Sci. 1999;896(1):30-47.

66. Ketheesan S, Rinaudo M, Berger M, Wenitong M, Juster RP, McEwen BS, Sarnyai Z. Stress, allostatic load andmental health in Indigenous Australians. Stress. 2020;23(5):509-18.

67. Berger M, Juster R-P, Sarnyai Z. Mental health consequences of stress and trauma: allostatic load markers for practice and policy with a focus on indigenous health. Australasian Psychiatry. 2015;23(6):644-9.

68. Davison B, Singh GR, McFarlane J. Hair cortisol and cortisone as markers of stress in Indigenous and non-Indigenous young adults. Stress. 2019;22(2): 210-20.

69. Berger M, Taylor S, Harriss L, Campbell S, Thompson F, Jones S, et al. Hair cortisol, allostatic load, and depressive symptoms in Australian Aboriginal and Torres Strait islander people. Stress. 2019;22(3):312-20.

70. Davison B, Singh GR, Oguoma VM, McFarlane J. Fingernail cortisol as a marker of chronic stress exposure in Indigenous and non-Indigenous young adults. Stress. 2020:23(3):298-307.

71. Slavich GM. Life Stress and Health: A Review of Conceptual Issues and Recent Findings. Teach Psychol. 2016:43(4):346-55.

72. Paradies $Y$, Harris $R$, Anderson I. The Impact of Racism on Indigenous Health in Australia and Aotearoa: Towards a Research Agenda. Darwin: Cooperative Research Centre for Aboriginal Health; 2008. Report No.: Discussion Paper No. 4.

73. Paradies Y, Cunningham J. Development and validation of the measure of indigenous racism experiences (MIRE). Int J Equity Health. 2008;7(1):9.

\section{Publisher's Note}

Springer Nature remains neutral with regard to jurisdictional claims in published maps and institutional affiliations. 